\title{
LA ACTIVIDAD PROBATORIA Y EL TERCERO IMPARCIAL EN EL MODELO ACUSATORIO CONTRADICTORIO DEL CÓDIGO PROCESAL PENAL \\ (DEC. LEG. N. ${ }^{\circ}$ 957)
}

\section{THE PROBATORY ACTIVITY AND THE IMPARTIAL THIRD PARTY IN THE CONTRADICTORY ACCOUNT MODEL OF THE CRIMINAL PROCEDURAL CODE (DEC. LEG. N. ${ }^{\circ}$ 957)}

\author{
Rodolfo Castro Medina \\ Abogado \\ Universidad de San Martín de Porres \\ rodolfoolgercastro@gmail.com
}

Perú

\section{SUMARIO}

- Introducción

- El modelo acusatorio contradictorio (desafíos actuales)

- El proceso de implementación

- Capacitación como entrenamiento

- El juez en el escenario de la actividad probatoria

- ¿Qué comprende ser el juez de juzgamiento dentro de un modelo acusatorio contradictorio?

- Principales principios que rigen el escenario de la actividad probatoria

- Principio acusatorio

- Principio de oralidad e inmediación

- Principio de publicidad

- Principio de contradicción y de igualdad procesal

- Conclusiones y recomendaciones

\section{RESUMEN}

Este artículo se ocupa en señalar y acreditar que el Código Procesal Penal del 2004, al considerar la etapa de juzgamiento como una fase principal del proceso penal normado bajo los principios de oralidad, publicidad, inmediación, contradicción e igualdad procesal, entre otros, demostraría una delimitación de funciones claramente establecida, tanto para las partes procesales como para el tercero imparcial, formando un escenario triádico en el juzgamiento. Por ello, más allá de la observación, control y dirección del juicio oral, sería contraproducente aceptar alguna intervención judicial en la actividad probatoria como lo prescribe también el citado código adjetivo.

Los objetivos del estudio son identificar qué principios procesales y estructurales que rigen el juicio oral son transgredidos con las facultades de intervención del juez de juzgamiento en el marco del Código Procesal Penal del 2004; analizar el concepto y atribuciones que comprende ser el tercero imparcial en el contexto de la actividad probatoria; identificar qué comprende la teoría del caso y qué sujetos procesales cuentan con esta; y concienciar a los operadores judiciales sobre lo que implica un cambio cultural en los sujetos procesales de cara a un modelo acusatorio contradictorio.

El autor enfatiza la necesidad de contar con un órgano jurisdiccional sin facultad de intervención (súper partes), donde el juez, como tercero neutral e imparcial, va a apreciar el debate entre el fiscal y el abogado defensor del acusado, y tendrá que valorar la actividad probatoria percibida directamente sobre los argumentos y medios de prueba presentados y examinados por los distintos intervinientes, sin suplir la actividad de las partes. Esto quiere decir que el juzgador, como tercero imparcial o «árbitro» entre las partes, reservará su intervención para observar, dirigir y controlar directamente el debate entre dichos 
sujetos procesales garantizando los derechos fundamentales de la persona. Para ello debe propiciarse la concienciación respecto al hecho de que la teoría del caso de las partes procesales, en igualdad de armas, es un plan estratégico de inicio a fin en el juzgamiento, y que los principios que rigen dicha etapa estelar son un conjunto de ideas fuerza de aplicación directa y necesaria que van a cautelar la actividad probatoria.

\section{ABSTRACT}

This article is concerned with pointing out and believing that the Criminal Procedure Code of 2004, considering the judgment stage as a main phase of the criminal proceedings under the principles of orality, publicity, immediacy, contradiction and procedural equality, among others, would demonstrate a clearly established delimitation of functions, both for the procedural parties, as well as for the impartial third party, forming a triadic scenario in the judgment. Therefore, beyond the observation, control and direction of the oral judgment, it would be counterproductive to accept some judicial intervention in the probative activity as also prescribed in the said adjective code.

The objectives of the study are to identify which procedural and structural principles that govern the oral trial are violated with the powers of intervention of the judge of judgment within the framework of the Code of Criminal Procedure of 2004; analyze the concept and attributions of being the impartial third party in the context of the probationary activity; identify what the theory of the case understands and which procedural subjects have it; and to make the judicial operators aware of what implies a cultural change in the procedural subjects in the face of a contradictory accusatory model.

The author emphasizes on the need to have a court with no powers of intervention (super parties), where the judge, as neutral and impartial third party, will appreciate the debate between the prosecutor and the defense lawyer of the accused, and It will have to assess the evidentiary activity received directly on the arguments and evidence presented and examined by the various parties, without supplementing the activity of the parties. This means that the judge, as impartial third party or "arbitrator" between the parties, will reserved his intervention to directly observe, direct and control the debate between these procedural subjects, guaranteeing the fundamental rights of the person. In order to achieve this, awareness must be given to the fact that the theory of the case of procedural parties, in equality of arms, is a strategic plan from beginning to end in the judgment and that the principles that govern this stellar stage are a set of Ideas force of direct and necessary application that will guard the probative activity.

\section{PALABRAS CLAVE}

Actividad probatoria, tercero imparcial, juzgamiento, modelo acusatorio, delimitación de funciones, técnicas de litigación oral, teoría del caso igualdad de armas

\section{KEYWORDS}

Trial activity, impartial third trial, accusatory model, delimitation of functions, techniques of oral litigation, theory of the case, equality of arms

\section{INTRODUCCIÓN}

Una reforma procesal penal de corte acusatorio contradictorio que asume el Código Procesal Penal del 2004 (Decreto Legislativo N. ${ }^{\circ}$ 957) le exige al juez de sentencia como tercero imparcial (no a cualquier juez), que por primera vez va a tener conocimiento del caso a raíz de los enunciados fácticos de las partes en igualdad de condiciones, llevar la dirección del juicio oral en su inicio, desarrollo y conclusión bajo principios como el acusatorio, de oralidad e inmediación, y de publicidad. Además, dirigirá los principios de contradicción y de igualdad procesal, recogidos en el artículo $1^{\circ}$ del Título Preliminar del mencionado código.

Esta aplicación de los principios de carácter procedimental y estructural que norman el juicio oral exigen al juez de juzgamiento, como tercero imparcial, ser un «árbitro» entre las partes, cuya intervención se reservaría a la observación, dirección y control directo del debate entre los sujetos procesales que en igualdad de condiciones o de armas ejercen el contradictorio, entiéndase el fiscal y la defensa, y que, a raíz de este ejercicio contradictorio de las posiciones dialécticas dentro del juicio oral, se daría la obtención o producción de la prueba. 
The probatory activity and the impartial third party in the contradictory account model of the Criminal Procedural Code (Dec. Leg. $N .^{\circ} 957$ )

Por consiguiente, el modelo acusatorio contradictorio que asume el novísimo Código Procesal Penal define la prueba como aquella actividad que realizan las partes procesales, dirigida a demostrar la evidencia necesaria (actividad de demostración) con la finalidad de obtener la convicción del juez decisor sobre los hechos que las partes afirman en la exposición de su teoría del caso. Así, en el desarrollo de la actividad probatoria se sigue la lógica de demostración de parte, propio de un sistema acusatorio contradictorio.

Asimismo, la citada norma procesal faculta a la vez la intervención jurisdiccional en el desarrollo de la actividad probatoria como un uso y costumbre del modelo inquisitivo bajo la premisa de la actividad de verificación judicial, donde el juez o tribunal decisor verifica, a través de su examen probatorio, la veracidad de las afirmaciones por parte de los sujetos procesales. Esta situación es descrita en el artículo 375.4, el cual señala que el juez puede intervenir durante el desarrollo de la actividad probatoria cuando lo considere necesario, a fin de que el fiscal o los abogados de las partes hagan los esclarecimientos que se les requiera $\mathrm{y}$, a la vez, agrega que por excepción puede interrogar a los órganos de prueba cuando hubiera quedado algún vacío.

Más aun, el artículo 376.3 señala que se permite al juez decisor declarar, de oficio, inadmisibles las preguntas prohibidas. Asimismo, el artículo 385.2 le permite, excepcionalmente, disponer de oficio la actuación de nuevos medios probatorios. Todo lo descrito refleja que la prueba es intervenida por el órgano jurisdiccional decisor bajo el contexto del principio de oficialidad.

No obstante, la gravedad del problema descrito es que se presenta en un nuevo proceso penal que asume un modelo acusatorio contradictorio y con delimitación de funciones, el cual supone un sistema de frenos en el ejercicio funcional de cada uno de los operadores de justicia dentro del escenario de la actividad probatoria En la prueba quedan comprometidas dos grandes garantías constitucionales, la del debido proceso y la del derecho de defensa procesal, con los correspondientes principios que están introducidos en estas, como el de contradicción y el de igualdad, principios de carácter estructural que definen la esencia del proceso de corte acusatorio contradictorio.
Los objetivos de este artículo están dirigidos a identificar qué principios procesales $y$ estructurales que rigen el juicio oral son transgredidos con las facultades de intervención del juez de juzgamiento en el marco del Código Procesal Penal del 2004; analizar el concepto y atribuciones que comprende ser el tercero imparcial en el contexto de la actividad probatoria; identificar qué comprende la teoría del caso y qué sujetos procesales cuentan con esta; y concienciar a los operadores judiciales sobre lo que implica un cambio cultural en los sujetos procesales de cara a un modelo acusatorio contradictorio.

A lo largo del trabajo se expondrán los hechos $\mathrm{y}$ razones que sostienen lo aseverado en el planteamiento del problema y se analizarán dentro del marco constitucional. Así, en el capítulo primero se revelarán los desafíos actuales que comprende asumir un modelo acusatorio contradictorio. Mientras que en el segundo capítulo se definirá el rol del tercero imparcial en el escenario de la actividad probatoria a la luz de los principios que la norman. Finalmente, se ofrecerán conclusiones $\mathrm{y}$ recomendaciones.

\section{EL MODELO ACUSATORIO CONTRADICTORIO (DESAFÍOS ACTUALES)}

\section{El proceso de implementación}

El Decreto Legislativo $N^{\circ} 958$ reguló el proceso de implementación y transitoriedad del Código Procesal Penal 2004 a través de los programas de capacitación para jueces, fiscales y personal auxiliar (artículos 4.7 y 11), así como el trámite de causas con el régimen anterior (artículo $\left.16^{\circ}\right)^{1} \mathrm{y}$, a la vez, con lo referente a la adecuación de denuncias y liquidación de procesos en etapa de investigación, artículo $18^{\circ}$ modificado por la Ley $N^{\circ} 28994$ del 1 de abril de $2007^{2}$. Este último señala la implementación

1 Trámite de causas con el régimen anterior:

16.1 Dos meses antes de la vigencia del Código en el distrito judicial o distritos judiciales que correspondan, previa coordinación, el Poder Judicial y el Ministerio Público designarán a los jueces y fiscales que continuarán, a partir de su vigencia, el trámite de las causas según el régimen procesal anterior. $[\ldots]$

1 6.2 Para estos efectos, los Órganos de Gobierno del Poder Judicial y del Ministerio Público dictarán las directivas correspondientes para la correcta ordenación del traslado de expedientes.

2 Art. $18^{\circ}$. Adecuación de denuncias y conclusión de procesos en etapa de investigación.

18.1 Corresponde al Poder Judicial y al Ministerio Público implementar una organización de despacho fiscal y judicial para conocer los nuevos 
de despachos fiscales y judiciales para conocer los nuevos procesos penales bajo el criterio de la carga cero, es decir, jueces y fiscales dedicados exclusivamente a concluir con los procesos penales iniciados antes de la vigencia del Código Procesal Penal 2004 y conforme al modelo antiguo ${ }^{3}$.

Ahora bien, este proceso de implementación y transitoriedad reveló la necesidad de cambiar la tradicional capacitación legal por la capacitación cultural en los operadores de justicia, a través de las llamadas técnicas de litigación oral, debido a que la oralidad es el medio de comunicación por excelencia en este proceso penal de corte acusatorio contradictorio ${ }^{4}$.

Por su parte, afirma Baytelman (2004:6-7)

procesos penales bajo el criterio de la carga cero, es decir, con jueces y fiscales dedicados exclusivamente a concluir con los procesos penales indicados antes de la vigencia del Código Procesal Penal y conforme al modelo antiguo.

18.2 Las denuncias que al entrar en vigencia del Código Procesal Penal 2004 se encuentren en el Ministerio Público, pendientes de calificar o en investigación preliminar, se adecuaran a sus disposiciones [...].

18.3 Los procesos penales en etapa de investigación, iniciados antes de entrar en vigencia el nuevo Código Procesal Penal, serán asumidos por los jueces y fiscales que se designen por el Poder Judicial y el Ministerio Público, respectivamente, para la conclusión progresiva de estos, bajo las normas del Código de Procedimientos Penales.

Antes de la modificación, el citado artículo señalaba:

Art. $18^{\circ}$. Transición de los procesos en etapa de investigación: Los procesos en curso que al entrar en vigencia este código no tengan sentencia, se sujetarán a las normas siguientes:

18.1. Los procesos ordinarios o sumarios que se encuentren en la etapa de investigación ante el juez penal continuarán tramitándose con el régimen procesal penal anterior hasta el vencimiento del plazo de instrucción o investigación o lo ampliatorio. Luego de cumplida esta etapa, se sujetarán a las normas del Código Procesal Penal.

18.2. Los procesos sumarios en trámite, una vez culminada la etapa de investigación, se tramitarán de acuerdo con las disposiciones señaladas por el Código Procesal Penal para el proceso común, con las siguientes precisiones:

a) Al concluir la investigación se remitirán los autos al fiscal provincial, quien emitirá dictamen pudiendo este solicitar por una sola vez la ampliación de la investigación, solicitar el archivo del proceso o formular acusación.

b) En caso que el fiscal provincial se abstenga de formular acusación, el juez podrá disponer el archivo del proceso o podrá elevar los autos al fiscal superior, luego de cuyo pronunciamiento, sin más trámite, deberá el juez expedir la resolución correspondiente.

3 Antes de esta modificación los jueces y fiscales asumian el conocimiento de los procesos penales que iniciaban, tanto con la vigencia del Código Procesal Penal 2004, como con los del modelo antiguo (caso distrito judicial de Huaura), provocando una sobrecarga procesal en parte de la administración de justicia, que asumía la implementación y transitoriedad del Código Procesal Penal.

4 Sobre el particular, refiere Binder (1993): «La oralidad representa, fundamentalmente, un medio de comunicación: la utilización de la palabra hablada, no escrita, como medio de comunicación entre las partes y el juez y como medio de expresión de los diferentes órganos de prueba [...]; obsérvese que, en el fondo, el mecanismo es simple: si se utiliza la palabra hablada, las personas deben estar presentes (inmediación) y, además, se comunican de un modo que es fácilmente controlable por otras personas (publicidad). Esta simpleza no ha sido siempre reconocida y aún hoy se escucha a quienes, sin fundamento alguno, afirman que el juicio oral es más complicado, más difícil de realizar que el escrito, donde todo se transcribe en actas (Quoa non est in actas, non est in mundo)"”. (p. 97)
Lo que realmente representa una barrera dificil de superar es que por primera vez requiramos una capacitación 'cultural' [...] más que una capacitación 'legal'. El sistema de capacitación tiene que remover una cultura y construir otra, tiene que destruir instituciones $e$ ideas profundamente arraigadas en nuestra cultura jurídica y, en cambio, sustituirlas con otras que, solo en la medida en que institucionalicen y se instalen dentro de nuestra cultura jurídica, lograrán realmente realizarse [...].

\section{Capacitación como entrenamiento}

Las técnicas de litigación oral suprimen todo concepto de improvisación o intuición, así como todo criterio de mera oratoria o capacidad histriónica, pues dicha disciplina cuenta con la formación de planes estratégicos para el desarrollo de una audiencia, sabiendo a la vez que el juicio oral se resume en un ejercicio $100 \%$ estratégico.

El término «estrategia» no comprende distorsionar la verdad para engañar sino, por el contrario, capacitar a las partes a través de distintos métodos o técnicas que les permitan formar en el juzgador una convicción de los hechos materia de probanza. Así, no basta con decir la verdad, sino que esta tiene que ser presentada de manera estratégica, porque la prueba no habla por sí sola sino a través de los litigantes.

En efecto, un litigante bien preparado puede presentar una prueba de una manera que revele toda la plenitud informativa que ella posee, como también un litigante mal preparado puede presentar esa misma prueba sin llegar a reflejar la importancia que esta contiene, pasando por inadvertida o insignificante, de modo que no capte la atención esperada en el juzgador.

Como se puede apreciar, esta disciplina busca desplazar la imagen de capacitación como instrucción por una nueva imagen de capacitación como entrenamiento a través de las técnicas de litigación oral, las cuales comprenden:

\section{La teoria del caso}

Al respecto, Baytelman y Duce (2003:56), sostienen: «La 'teoría del caso', en suma, es 
The probatory activity and the impartial third party in the contradictory account model of the Criminal Procedural Code (Dec. Leg. N. ${ }^{\circ}$ 957)

nuestra simple lógica y persuasiva historia acerca de 'lo que realmente ocurrió'. Como tal, debe ser capaz de combinar coherentemente nuestra evidencia indiscriminada con nuestra versión acerca de la evidencia controvertida que se presentará en el juicio».

En ese sentido, comprende un plan estratégico de inicio a fin en el juzgamiento ${ }^{5}$, que lleva consigo desde su presentación en la audiencia (alegato de apertura), hasta la preparación de los testigos y el orden en que estos deben de ser actuados, es decir, la forma en que la parte procesal tiene que examinar a sus propios testigos para poder extraer de ellos la información que dicha teoría del caso requiere $y$, a la vez, poder fortalecer su credibilidad ante los ojos del juzgador; segundo, la forma de contraexaminar a los testigos de la contraparte y poder revelar los defectos de su testimonio; tercero, la forma de examinar y contraexaminar peritos; y cuarto, la forma de utilizar la prueba material y documental, etc.

El propósito es proveer al juzgador, como tercero imparcial o «árbitro», una información contrastada de primer nivel que lleve a confirmar la veracidad de la historia o plan estratégico, pues es el juez de juzgamiento a quien se le debe convencer sobre la teoría del caso mediante la actuación de pruebas. Así, la teoría del caso se resume a un plan estratégico o la historia que cada parte procesal tiene sobre el caso y que se refleja desde el inicio del juicio oral mediante el alegato de apertura o alegato preliminar.

\section{Alegato de apertura o discurso}

Es la exposición que se hace sobre la teoría del caso ante el juez o tribunal y con base en la prueba que se va presentar.

Por ejemplo, el artículo 371.2 del Código Procesal Penal 2004 establece que, al hacerse la apertura del juicio, el fiscal expondrá resumidamente los hechos objeto de la acusación, la calificación jurídica y las pruebas que ofreció y fueron admitidas. Posteriormente, en su orden, los abogados del actor civil y del tercero civil expondrán concisamente sus pretensiones y las pruebas ofrecidas $\mathrm{y}$ admitidas. Finalmente, el defensor del acusado expondrá brevemente sus argumentos de 5 Como también, una estrategia en todo el proceso penal (artículo 65.4 del
NCPP). defensa y las pruebas de descargo ofrecidas y admitidas.

Este alegato de apertura es la oportunidad para que las partes procesales puedan lograr un primer impacto sobre su teoría en el juzgador $\mathrm{y}$, a la vez, la oportunidad de anticipar $\mathrm{y}$ exponer lo que será su prueba en el contexto de su teoría. Dicho discurso puede tener como base la siguiente estructura:

- Narrar los hechos en forma cronológica: contar los hechos que van a salir demostrados mediante la prueba.

- Criticar de forma indirecta las alegaciones o probables defensas o ataques de la parte contraria para quitarle efectividad a las mismas; anticipar lo que va a decir.

- Cerrar el alegato comprometiendo al juzgador con la promesa de prueba.

Al respecto, refieren Baytelman y Duce (2003:40): « [...] el mecanismo natural de trasmisión es el relato. Pero al litigante no le bastará — para ser bueno - tan solo que su historia sea entretenida o interesante, sino que ella deberá trasmitir al tribunal de que se trata de la versión más fidedigna de los hechos y la interpretación de la teoría más adecuada y justa».

\section{Examen directo}

Es el primer examen que se le hace a un declarante $u$ órgano de prueba por la parte que lo ha propuesto, conforme a lo estipulado en el artículo 375.3 del debate probatorio.

Por ejemplo, las partes preparan a sus testigos para que puedan proporcionar al juzgador información necesaria cuando sean examinados, de tal manera que fortalezca la teoría de quien lo presentó.

Así, el examen directo, al ser parte de la teoría del caso, lleva consigo un plan estratégico elaborado antes de que el testigo ingrese a la actuación probatoria, como refieren Baytelman y Duce (2003:59): " [...] examen directo es extraer del testigo la información que requerimos para construir el trozo de historia que este nos puede proporcionar. Esta es la etapa en que elaboramos la mayor parte de nuestra versión de los hechos, nuestra 'teoría del caso'». 
$\mathrm{Su}$ correcta elaboración permite plasmar, mediante la declaración del testigo, elementos que la parte procesal se propone probar, no solo diciendo la verdad sino que además debe parecer creíble, como afirma Fumero (2004:2): «Para ser creíble un testigo no solo es suficiente que diga la verdad sino que es importante aconsejarlo que, mediante su comportamiento correcto y sereno mientras declara y mediante la seguridad de sus respuestas, debe además parecer que está diciendo la verdad».

Esta preparación comprende el orden de presentación de los órganos de prueba. Por ejemplo, cuando se trate de varios testigos, la presentación de estos llevará varios días para que puedan establecer los hechos. Frente a ello, el orden en su presentación debe de ser estratégico, por lo cual se tiene que presentar un testigo impactante al inicio y otro al final, para poder lograr durante toda la actuación probatoria, de inicio a fin, la atención completa del juzgador. Por el contrario, si presentamos todos los testigos impactantes al inicio, el juzgador puede perder el interés cuando posteriormente declaren los testigos que solo aportan cuestiones técnicas o elementos de menor importancia. Ellos deben de ir en la parte media, en el orden de presentación de la prueba testimonial.

Esta elaboración exige una estrategia en la organización de preguntas, por ejemplo, aquellas que permitan acreditar al testigo, para ser fuente creíble; para producir respuestas en orden cronológico, dirigidas a que el juzgador pueda visualizar los hechos y seguir con más comprensión la prueba; resaltar con preguntas asuntos importantes; y finalizar con preguntas que produzcan una contestación impactante sobre un aspecto importante.

Asimismo, debe sumarse la forma de hacer las preguntas. Por ejemplo, las abiertas ¿cómo...?, ¿dónde...?, ¿cuándo...?, ¿qué paso...?, ¿explique...?, entre otras, para que sea el propio testigo quien informe al juzgador sobre los hechos, pues estas preguntas dan la posibilidad de que pueda explayarse en sus declaraciones; preguntas simples que puedan ser entendidas; preguntas de emergencia, si el caso lo requiere, para poder ubicar u orientar al testigo; y preguntas que permitan al testigo explicar o describir los hechos que narra.
Por otro lado, en este examen se prohíben las preguntas capciosas, impertinentes, repetitivas, sugestivas, por opinión, compuestas y argumentativas.

\section{Contraexamen}

Es el examen que lleva a cabo la parte contraria inmediatamente después que un órgano de prueba fue objeto de un examen directo, conforme lo estipulado en el artículo 378.8 del debate probatorio.

Teniendo como propósito tachar la credibilidad del testigo o perito de la parte contraria, así como lograr que el testigo reconozca o resalte aspectos positivos para nuestra teoría y que reconozca o resalte aspectos negativos del caso contrario, entre otros, refieren Baytelman y Duce (2003:92):

\section{[...] al sistema le interesa enormemente, entonces, que las partes tengan amplias posibilidades de contraexaminar la prueba presentada por la otra; $y$, aunque el derecho de defensa presiona todavía un poco más la lógica de la contrariedad a favor de la defensa, lo cierto es que al sistema le interesa crucialmente que ambas partes - tanto fiscalía como imputado - tengan amplias posibilidades de controvertir la prueba en condiciones de juego justo.}

A la vez, se requiere de un orden para las preguntas, a fin de no repetir el examen directo ni realizar preguntas sobre los hechos de manera cronológica, así como saber cuándo es necesario preguntar y cuando acabar el contraexamen. La forma de hacer las preguntas es esencial, no preguntas abiertas ni preguntas que permitan al testigo dar explicaciones o explayarse sobre los hechos expuestos en el examen directo, sino solo preguntar cuando se tenga conocimiento de la respuesta del testigo y no discutir o argumentar con él. Sumado a ello, y por tratarse de un contraexamen, hay uso mayoritario de preguntas sugestivas.

Asimismo, se debe cuestionar al testigo cuando demuestre incapacidad para percibir los hechos, por estar parcializado al tener algún prejuicio o interés en el caso, entre otros motivos.

Ahora bien, para hacer efectivas estas pautas en el contraexamen, se debe haber 
The probatory activity and the impartial third party in the contradictory account model of the Criminal Procedural Code (Dec. Leg. N. ${ }^{\circ}$ 957)

investigado previamente a los testigos por sus declaraciones preliminares a fin de conocer los puntos que van a utilizar en el examen directo. El contraexamen, al igual que el examen directo, no es improvisación, pues una respuesta inesperada puede afectar la teoría del caso del litigante.

\section{Objeciones}

Las partes procesales en litigio, haciendo uso del principio de contradictoriedad, pueden oponerse en el preciso momento en que la contraparte ofrece una prueba que sea inadmisible o cuando hace preguntas impertinentes, capciosas, por opinión, repetitivas, compuestas, argumentativas y sugestivas, esta última prohibida en el examen directo pero permitida y recomendable en el contraexamen.

\section{Alegato de clausura o argumento final}

Es la última oportunidad de comunicarse directamente con el juez y fijar los puntos que se demostraron en la actividad probatoria y que fueron en el alegato de apertura una promesa de prueba, es decir, argumentar solo lo que se demostró dentro del debate probatorio. Por ejemplo, el litigante no puede argumentar en el alegato final hechos que desacrediten a un testigo que no hayan sido producidos en el contraexamen.

En definitiva, al ser el juzgamiento un escenario de hechos más que de normas, las técnicas de litigación oral cumplen un rol de preparación importante en un modelo acusatorio contradictorio.

\section{EL JUEZ EN EL ESCENARIO DE LA ACTIVIDAD PROBATORIA}

En este capítulo se desarrolla lo que comprende el juicio oral dentro de un modelo acusatorio contradictorio como escenario de la actividad probatoria, regido bajo principios como el acusatorio, de oralidad e inmediación, y principio de publicidad, así como los de contradicción y de igualdad procesal. A la vez, se conocerá cómo deberían entenderse estos citados principios de carácter procedimental y de carácter estructural que norman el juicio oral, y que exigen al juez de juzgamiento como tercero imparcial ser un «árbitro» entre las partes.
¿Qué comprende ser el juez de juzgamiento dentro de un modelo acusatorio contradictorio?

La importancia del juzgamiento no radica en ser oral, sino en que dicha oralidad permita ejercer el contradictorio. Al ser contradictorio, el juzgamiento se resume a un escenario sumamente estratégico, el cual lleva a una preparación de la teoría del caso de las partes procesales en litigio, como refieren Baytelman y Duce (2003:39): " [...] el juicio oral es un ejercicio profundamente estratégico, en un específico sentido: La prueba no habla por sí sola. La prueba debe ser presentada y puesta al servicio de nuestro relato, nuestra versión acerca de qué fue lo que realmente ocurrió $[\ldots] »$.

Al ser acusatorio, el juez como tercero imparcial cumple funciones de dirección, control y observación del debate probatorio entre el fiscal y la defensa del acusado, quienes son llamados para presentar la prueba; es decir, partiendo de una separación de roles entre los sujetos procesales, el órgano juzgador no tiene que probar nada, no cuenta con una teoría del caso.

En ese sentido, la etapa de juzgamiento es dirigida por el juez unipersonal o colegiado, que en rigor a una reforma procesal penal de corte acusatorio contradictorio que asume el Código Procesal Penal del 2004 le exige al juez de sentencia (no a cualquier juez), como tercero imparcial - que por primera vez va a tener conocimiento del caso a raíz de los enunciados fácticos de las partes en igualdad de condiciones - llevar la dirección del juicio oral en su inicio, desarrollo y conclusión bajo principios, como los ya citados principio acusatorio, de oralidad e inmediación, y de publicidad, así como los de contradicción y de igualdad procesal, recogidos en el artículo 1. ${ }^{\circ}$ del Título Preliminar del mencionado código adjetivo.

Esta aplicación de los principios de carácter procedimental y de carácter estructural que norman el juicio oral exigen al juez de juzgamiento, como tercero imparcial, ser un «árbitro» entre las partes, cuya intervención se reservaría a la observación, dirección y control directo del debate entre los sujetos procesales, que en igualdad de condiciones o igualdad de armas ejercen el contradictorio - entiéndase el fiscal y la defensa - y que a raíz de este ejercicio contradictorio de las posiciones 
dialécticas dentro del juicio oral se daría la obtención o producción de la prueba.

En ese sentido, este código define la prueba como aquella actividad que realizan las partes procesales, dirigida a demostrar la evidencia necesaria con la finalidad de obtener la convicción del juez decisor sobre los hechos que las partes afirman en la exposición de su teoría del caso. Por tal motivo, en el desarrollo de la actividad probatoria se sigue la lógica de demostración de parte, el cual es propio de un modelo acusatorio contradictorio como el que asume el presente código.

Así, el juicio oral es un test de calidad de información directamente percibido por los jueces dentro de un marco de principios por el cual se rige, como el de publicidad, el cual permite que cualquier persona tenga conocimiento de la audiencia como escenario principal de producción de la prueba. En tanto, la oralidad es instrumento de comunicación de quien acusa y contradice los cargos que se le imputan, principio que se encuentra íntimamente ligado al llamado principio de inmediación, que no es otra cosa que la relación directa entre el juez y las partes, así como los órganos de prueba.

Sobre el particular, define Binder (1993:233): «Es la etapa principal del proceso penal porque es allí donde se resuelve o 'redefine' de un modo definitivo....». Así como Roxin (2000:358): «El juicio oral es considerado el punto culminante de todo proceso penal».

Principales principios que rigen el escenario de la actividad probatoria

El inicio, desarrollo y conclusión de la actividad probatoria se rigen principalmente por los siguientes principios:

\section{Principio acusatorio}

Comprende la división de poderes, por un lado, del acusador, quien ejerce el poder persecutorio, y por otro, el tribunal, quien ejerce el poder de decisión.

Por este principio, esencia del sistema acusatorio, se comprende la necesidad de una acusación previa por el fiscal para que se inicie el juzgamiento por parte del juez; a la vez, división de poderes, que comprende un sistema de frenos en el ejercicio de cada uno de los sujetos procesales, de modo tal que quien ejerza un determinado rol se controle dentro del equilibrio funcional, tanto para las funciones de persecución, como de defensa y función juzgadora.

Esta situación exige una delimitación de funciones claramente establecida, tanto para las partes procesales como para el tercero imparcial, formando un escenario triádico en el juzgamiento. Por ello, sería contraproducente aceptar alguna intervención del juez decisor en la actividad probatoria, más allá de la observación, control y dirección del juicio.

No obstante, a lo comprende este principio, el Código Procesal Penal del 2004 faculta la intervención jurisdiccional en el desarrollo de la actividad probatoria, bajo la premisa de la actividad de verificación judicial, donde el juez o tribunal decisor verifica, a través de su examen probatorio, la veracidad de las afirmaciones por parte de los sujetos procesales. Este escenario está reflejado en el artículo 375.4, el cual señala que el juez puede intervenir durante el desarrollo de la actividad probatoria cuando lo considere necesario, a fin de que el fiscal o los abogados de las partes hagan los esclarecimientos que se les requiera $\mathrm{y}$, a la vez, agrega que por excepción puede interrogar a los órganos de prueba cuando hubiera quedado algún vacío.

Sumado a ello, el artículo 376.3 señala que se le permite al juez decisor declarar, de oficio, inadmisibles las preguntas prohibidas. Asimismo, el artículo 385.2 faculta al juez decisor, excepcionalmente, disponer de oficio la actuación de nuevos medios probatorios.

Todo lo cual refleja que la prueba es intervenida por el órgano jurisdiccional decisor bajo el contexto del principio de oficialidad.

\section{Principio de oralidad e inmediación}

Este principio exige que las personas declaren a través de la palabra hablada, de modo que puedan ser oídas directamente por los jueces, llevando ineludiblemente al juzgador a un contacto personal y directo con las partes y con los órganos de prueba (principio de inmediación). Con ello, estos perciben tanto su comunicación oral como corporal (si muestra nerviosismo al hablar, si traspira, si se ruboriza). Entonces, la oralidad es un 
The probatory activity and the impartial third party in the contradictory account model of the Criminal Procedural Code (Dec. Leg. N. ${ }^{\circ}$ 957)

instrumento que lleva inevitablemente a la inmediación, como refiere Barona (1994:201): « [...] El principio de oralidad sirve con ello también, como principio de inmediación, para garantizar en interés de la averiguación de la verdad, la impresión personal de las declaraciones del imputado y de los testigos».

Este principio garantiza una decisión judicial por quien presenció, personal y directamente, la actividad probatoria, como agrega también Barona (1994:197):

\section{[...] significa que el juez debe dictar su sentencia en base a la impresión personal que haya obtenido respecto del imputado y de la práctica de los medios de prueba. [...] El aspecto formal supone que en el juicio oral deben practicarse y seguirse las pruebas directamente por el juzgador. De ahí la necesidad de lo que se exige en el de la presencia ininterrumpida de las personas llamadas a la formación de la sentencia. Por ello, deben excluirse como fundamentación de la sentencia todas aquellas fuentes y materiales que se hayan obtenido fuera del desarrollo de la vista.}

En definitiva, los principios de oralidad y de inmediación permiten el deseable contacto vivido e inmediato con las partes y la prueba, $y$, así, la posibilidad de establecer la indispensable relación comunicacional entre el juzgador y la personalidad del acusado.

\section{Principio de publicidad}

Es el principio de control del juzgamiento y fiscalización de la actividad realizada por los operadores de justicia, pues toda persona tiene derecho a presenciar el juicio oral y a observar la manera en que los jueces, fiscales y abogados ejercen su labor dentro de la actuación probatoria. Como afirma Binder (1993:104): " [...] de este modo, que los jueces deben dictar sus sentencias "de cara al pueblo". Y los ciudadanos pueden tener una percepción directa de cómo ellos utilizan ese enorme poder que la sociedad les ha confiado. Debe quedar claro, pues, que la publicidad del juicio es el principio que asegura el control ciudadano sobre la justicia». En ese sentido, la publicidad, como transparencia de la administración de justicia, permite a la sociedad ver y escuchar lo que hacen los jueces y cómo llegan a las decisiones que adoptan.
Asimismo, la publicidad implica que los medios de comunicación social (publicidad mediata) puedan fotografiar, filmar o transmitir la audiencia, salvo restricciones, y que la comunidad pueda formular sus propios conceptos respecto de la actividad jurisdiccional.

\section{Principio de contradicción y de igualdad procesal}

Implica que las partes puedan realizar toda la actividad que esté a su alcance para replicar o contradecir las afirmaciones de la contraparte en igualdad de condiciones o igualdad de armas. Como afirma en un extremo Mixán (2003:67): " [...] es el fundamento de la ineludible designación del defensor del acusado a fin de que, en correlación de opuestos, efectúe el control técnico-jurídico de la acusación durante el juicio oral, ya sea aportando nuevas pruebas, refutando las preexistentes, orientando a su defendido, contra argumentando, etc.».

En definitiva, al entenderse estos principios, se pretende una igualdad de posibilidades para las partes actuantes, por lo cual de ninguna manera hay preponderancia del fiscal o de la defensa.

Estos principios alcanzan su máxima expresión en el momento de la acusación y la defensa. Es decir, el fiscal, como representante del Ministerio Público, expone la acusación, y el abogado del acusado debe plantear la defensa ante los argumentos esgrimidos por el fiscal, replicando el ataque. A la vez, en razón a estos principios, el juzgador tendrá que valorar la prueba percibida directamente sobre los argumentos y aquellas presentadas por los distintos intervinientes, sin suplir la actividad de las partes. Es decir, el juzgador, como tercero imparcial o «árbitro» entre las partes, reservará su intervención para observar, dirigir y controlar directamente el debate entre dichos sujetos procesales, garantizando los derechos fundamentales de la persona y el respeto a las garantías del debido proceso.

En ese sentido, para lograr este panorama, es importante que el juez no tenga facultades de intervención durante el desarrollo de la actividad probatoria, más allá de sus poderes de observación, dirección y control del juicio. Por ejemplo, sería incorrecta la facultad del juez de interrogar a los órganos de prueba, declarar de oficio inadmisibles las preguntas 
prohibidas o disponer de oficio la actuación de nuevos medios probatorios.

Porque la facultad del juez de interrogar a los órganos de prueba menoscaba su imparcialidad, por ser la parte procesal la que produce las pruebas con la finalidad de obtener la convicción del juez decisor sobre los hechos que las partes afirman en la exposición de su teoría del caso, en el desarrollo de la actividad probatoria que sigue la lógica de demostración de parte, propio de un sistema acusatorio contradictorio.

A la vez, porque la inadmisibilidad de oficio de las preguntas prohibidas afecta la estrategia de la parte procesal, por lo que el juez debe dejar que solo las partes objeten, ya que ellas tienen su teoría del caso, han investigado a los testigos y peritos, y están en mejores condiciones que el juez para determinar si les conviene objetar la pregunta o no.

Asimismo, la actuación de la prueba de oficio atenta contra la teoría del caso de la parte procesal, porque el juez, como tercero imparcial, no tiene una pretensión o plan para probar los hechos, por lo que debe permitir la igualdad de armas entre las partes en conflicto, quienes a través de una posición contradictoria buscan probar su plan o teoría del caso.

\section{CONCLUSIONES}

La intervención del juzgador en la actividad probatoria vulnera los principios de contradicción y de igualdad procesal que norman el juicio oral.

La facultad del juez de interrogar a los órganos de prueba menoscaba su imparcialidad, porque es la parte procesal la que produce las pruebas con la finalidad de obtener la convicción del juez decisor sobre los hechos que las partes afirman en la exposición de su teoría del caso.

La inadmisibilidad de oficio de las preguntas prohibidas afecta la estrategia de la parte procesal. Por ello, el juez debe dejar que solo las partes objeten, ya que ellas tienen la teoría del caso y, están en condiciones para determinar si les conviene o no objetar la pregunta.

La actuación de la prueba de oficio atenta contra la teoría del caso de la parte procesal, porque el juez, como tercero imparcial, no tiene una pretensión o plan para probar los hechos.
Se debe contar con un órgano jurisdiccional sin facultad de intervención (súper partes), donde el juez, como tercero neutral e imparcial, aprecie el debate entre el fiscal y el abogado defensor del acusado y valoré la actividad probatoria percibida directamente sobre los argumentos y medios de prueba presentados y examinados por los distintos intervinientes en conflicto.

El juzgador, como tercero imparcial entre las partes en conflicto, se reservará su intervención para observar, dirigir y controlar directamente el debate entre dichos sujetos procesales, garantizando la igualdad de armas y demás derechos fundamentales de la persona, sin suplir la actividad de las partes.

Los principios que rigen el juicio oral son un conjunto de reglas que van a cautelar la iniciación, desarrollo y conclusión de la actividad probatoria.

\section{RECOMENDACIONES}

Modificar el artículo 375.4, el cual quedará redactado en los siguientes términos:

«Artículo 375. Orden y modalidad del debate probatorio.

\section{$[\ldots]$}

4. El juez, durante el desarrollo de la actividad probatoria, ejerce sus poderes de observación, dirección y control, sin facultad de intervención».

Modificar el artículo 376.3, el cual quedará redactado en los siguientes términos:

«Artículo 376. Declaración del acusado.

[...]

3. El juez ejercerá puntualmente sus poderes de dirección y declarará, a solicitud de parte, inadmisibles las preguntas prohibidas».

Modificar el artículo 385.2, el cual quedará redactado en los siguientes términos:

«Artículo 385. Otros medios de prueba.

$[\ldots]$

2. Excepcionalmente, una vez culminada la recepción de las pruebas, el juez penal podrá 
The probatory activity and the impartial third party in the contradictory account model of the Criminal Procedural Code (Dec. Leg. N. ${ }^{\circ}$ 957)

disponer, a pedido de parte, la actuación de nuevos medios probatorios si en el curso del debate resultasen indispensables o manifiestamente útiles».

Intensificar la capacitación en técnicas de litigación oral dentro de un modelo acusatorio contradictorio en todas las facultades y escuelas de posgrado en Derecho, a fin de que se permita a los operadores del derecho un entrenamiento constante.

Concienciar a los operadores judiciales sobre lo que implica un cambio cultural en los sujetos procesales de cara a un modelo acusatorio contradictorio, a fin de que se remueva una cultura y se construya otra.

\section{REFERENCIAS}

Barona, S. (1994). "La conformidad en el proceso penal". Valencia: Tirant lo Blanch.

Baytelman, A. (2004). “Capacitación como Fútbol". Curso sobre Instrumentos para la Implementación de un Sistema Acusatorio Oral - Módulo sobre Capacitación para la Reforma Procesal Penal. Temuco.

Baytelman, A. y Duce, M. (2003). "Materiales de destrezas de litigación en juicio oral para el Ecuador". Instituto de Ciencias Procesal Penal.

Binder, A. (1993). "Introducción al derecho procesal pena”l. Buenos Aires: Ad-Hoc.

Código Procesal Penal del 2004.

Fumero, F. (2004). "Taller de Capacitación de Capacitadores. Módulo «Técnicas de Oralidad y Derecho Probatorio»". Guía para capacitadores. Lima: IRIS - USAID.

Mixán, F. (2003). "Juicio oral” (6 $6^{\mathrm{a}}$ ed.). Trujillo: Ediciones BLG.

Roxin, C. (2000). "Derecho procesal penal”. Buenos Aires: Editores del Puerto SRL.

\section{BIBLIOGRAFÍA}

Asencio, J. (1991). "Principio acusatorio $y$ derecho de defensa en el proceso penal". Madrid: Editorial Trivium S.A.

Azabache, C. (2003). "Introducción al procedimiento penal". Lima: Palestra Editores.
Baytelman, A. y Duce, M. (2003). "Evaluación de la reforma procesal penal". Santiago: Universidad Diego Portales.

Baytelman, A. y Duce, M. (2001). “Litigación penal en juicios orales" ( $2^{\circ}$ ed.). Santiago: Universidad Diego Portales.

Baytelman, A. y otros. (2003). "Desafios de la reforma procesal penal en el contexto latinoamericano". Lima: Academia de la Magistratura.

Binder, A. (1997). "Política criminal de la formulación a la praxis”. Buenos Aires: AdHoc.

Binder, A. (2002). "Iniciación al proceso penal acusatorio”. Lima: Editorial Alternativas.

Binder, A. (1993). "Justicia penal y estado de derecho”. Buenos aires: Ad-Hoc.

Bovino, A. (1998). "Problemas del derecho procesal penal contemporáneo”. Buenos Aires: Editorial del Puerto.

Cafferata, J. (1999). "Cuestiones actuales sobre el proceso penal". Córdova: Editores del Puerto.

Cafferata, J. (2000). "Proceso penal y derechos humanos”. Buenos aires: Editores del Puerto.

Castro, R. (2003). "Un juicio oral real como test de calidad constitucional de la información y escenario principal de la obtención y valoración de la prueba”. Lima: Universidad de San Martín de Porres, Facultad de Derecho y Ciencia Política. Instituto de Investigación Jurídica.

Chiesa, E. (1995). “Derecho procesal penal de Puerto Rico y Estados Unidos”. Colombia: Editorial Forum, V. III.

Duce, M. y Riego, C. (2002). "Introducción al nuevo sistema procesal penal”. Santiago: Universidad Diego Portales.

Ferrajoli, L. (1998). "Derecho y razón” (3 ed.). Madrid: Editorial Trotta.

Ferrajoli, L. (1999). “Derechos y garantías”. Madrid: Editorial Trotta.

Gómez, J. y Gonzáles, J. (1997). “La reforma de la justicia penal”. Castellón: Úniversitat Jaume-I. 
Gómez, J. (1998). "La exclusión del abogado defensor de elección en el proceso penal". Barcelona: Librería Bosch.

López, J. (1999). “Instituciones de derecho procesal penal”. Madrid: Ediciones Akal.

Lorca, A. (1997). "El proceso penal de la ley de enjuiciamiento criminal". Madrid: Editorial Dykinson, S.L.

Maier, J. (1982). "La ordenanza procesal penal alemana". Buenos Aires: Ediciones Depalma, V.II.

Maier, J. (1989). "Derecho procesal argentino" (2. ${ }^{a}$ ed.). Buenos Aires: Editorial Hammurabi S.R.L., Vol. A -B.

Maier, J. (2002). "Derecho procesal penal" (2. ${ }^{a}$ ed.). Buenos Aires, Editores del Puerto. T. I - II.

Miranda, M. (1997). "La mínima actividad probatoria en el proceso penal". Barcelona: J. M. Bosch Editor.
Montero, J. (1996). "Ensayos de derecho procesal". Barcelona: J. M. Bosch Editor.

Oré, A. (1999). “Manual de derecho procesal penal" ( $2^{\mathrm{a}}$ ed.). Lima: Editorial Alternativas.

Quiñones, H. (2003). “Las técnicas de litigación oral en el proceso penal salvadoreño". El Salvador: Talleres Gráficos.

Roxin, C. (2000). "La evolución de la política criminal, el derecho penal y el proceso penal". Valencia, Tirant lo Blanch.

Schonbohm, H. y Losing, N. (1995). "Sistema acusatorio juicio oral en América Latina". Caracas: Fundación Konrad Adenauer.

Sancinetti, M. (2001). "La violación a la garantía de la imparcialidad del tribunal". Buenos Aires: Ad-Hoc.

San Martín, C. (2003). "Derecho procesal penal” (2. ${ }^{a}$ ed.). Lima, Grijley. V. I - II. 